\title{
Relationship between Emotional Intelligence and the Academic Achievement among College Students
}

\author{
Pavithra Raj ${ }^{1}$, Dr. V. Chandramohan ${ }^{2}$
}

\section{ABSTRACT:}

Emotional Intelligence (EI) is considered as a successful predictor of academic achievement. Researchers have claimed that EI predicts success in schools/colleges/universities. The present study is an attempt in this direction. Three hundred Post-graduate girl Psychology students, studying at Indian Institute of Psychological Research, Bangalore, constituted as a sample for the present study. The students were administered with Emotional Intelligence Scale to measure their EI. EI score were compared with final semester examination marks. EI in its five domains such as Self-recognition, Self-regulation, Self-motivation, Empathy and Handling relations was positively associated with academic achievement. Over all EI score showed that $23 \%$ of the students were emotionally intelligent and excellent on academic achievement. Students, who were high on EI, were academically excellent. Results clearly indicated that there is a significant difference $(\mathrm{P}>0.0001)$ existing between the EI and academic achievement among college students. EI played a major role in promoting academic achievement among college students. Also, the study has brought out the fact that the emotional well being could be emphasized on academic achievement

Keywords: Emotional intelligence, academic achievement, psychology students, empathy

Emotional intelligence theory was originally developed by the research work / writings of Harvard Gardener (Harvard), Peter Solovey (Yale) John Mayer (New Hampshire) during the 1970's and 1980's. Daniel Colman's book entitled as "Emotional Intelligence” identifies 5 domains of Emotional Quotient such as Self - recognition (knowing your emotions), Self regulation (managing your emotions), Self - motivation (motivating yourself) Empathy (recognizing and understanding others emotions) and Handling relations (managing emotions of others). (Nelson and Low, 2003; Solovey and Mayer, 1990).

Development of EI is an intentional, active and engaging process (Nelson and Low, 2003). By developing EI, one can become more productive and successful.

${ }^{1}$ Research Scholar, Department of Psychology, Bharathiar University, Coimbatore

${ }^{2}$ Assistant Professor of Psychology, Mount Carmel College, Bangalore University, Bangalore, Research Supervisor, Reader in Psychology, Institute of Aerospace Medicine, IAF, Vimanapura (PO), Bangalore

(C) 2015 I P Raj, V Chandramohan; licensee IJIP. This is an Open Access Research distributed under the terms of the Creative Commons Attribution License (http://creativecommons.org/licenses/by/2.0), which permits unrestricted use, distribution, and reproduction in any Medium, provided the original work is properly cited. 
EI appears to be a core ingredient that, when developed and well employed, has wide ranging benefits for learning, relationship and wellness Academic achievement and academic performance have been determined by variables such as family, school, society and motivational factors (Aremu, 2004). Dr Parthasarathy (2000), HOD, Dept. of Social Work, NIMHANS, has highlighted the role of parents and teachers in cultivating emotional intelligence (Attaches as Appendix).

Jaeger (2003) delineated the fact that EI and academic achievement are positively correlated. Abisamra (2000) reported that there is a positive relationship between academic achievement and EI. Majority of the research suggests that EI abilities lead to superior performance even in the most intellectual career. EI predicts academic achievement (Zee, et al., (2000); Parker, et a;., 2004; Marquez Martin, et al., 2006). The present study was carried out to test this assertion on final year Post - graduate Psychology girl students. .

\section{AIM}

Aim of the present study was to find out the relationship between EI and academic achievement among college students

\section{OBJECTIVE}

EI plays a major role in the academic achievement. Once it is identified at an early stage, students can be helped to develop EI so that they will be successful in the academic achievement.

The other objectives were to assess the relative effect of the measured EI with regard to five dimensions of EI such as Self-recognition, Self-regulation, Self-motivation, Empathy and Handling relationship to academic achievement, Development of EI reduces attrition rate among college students. Emotionally intelligent student can work efficiently in the workplace.

\section{MATERIALS AND METHOD}

Three hundred healthy and well motivated final year, M.Sc., Psychology girl students, age ranging from 23 to 25 years, studying at Indian Institute of Psychological Research, Bangalore, constituted as a sample for the present study (Table 1)..

Table 1: Sample Characteristics

\begin{tabular}{|l|c|}
\hline \multicolumn{1}{|c|}{ DISCIPLINE } & NUMBER \\
\hline M.Sc., CLINICAL PSYCHOLOGY & 100 \\
\hline M.Sc., COUNSELLING PSYCHOLOGY & 100 \\
\hline M.Sc., INDUSTRIAL PSYCHOLOGY & 100 \\
\hline
\end{tabular}

Table 1 showed sample characteristics. Out of 300 girl students, 100 girl students each were studying Clinical Psychology, Counselling Psychology and Industrial Psychology Hence, 
the sample selected for the study was a homogeneous sample. Students were administered with Emotional Intelligence Scale to measure EI. All the girl students were studying psychology as a main discipline in Post - graduation, hence, the sample selected for the study was homogenous sample.

Short details of the psychological test, is as follows:

Emotional Intelligence Scale (EIS) has been developed by Schutle et al., (1998) to measure emotional intelligence. It is a five point rating scale and the ratings are Strongly Agree, Agree, Neutral, Disagree and Strongly Disagree, which measures five domains of EI such as Selfrecognition (knowing your emotions), Self-regulation (managing your emotions), Selfmotivation (motivating yourself) Empathy (recognizing and understanding others emotions) and Handling relations (managing emotions of others). College students are asked to record their responses on a separate answer sheet. There are 33 items and usually it takes 20 minutes to complete the test.

Scoring: Each correct answer is awarded with marks. Minimum raw score is 33 and the maximum 165. Out of 33, seventeen items are reverse scored and they are 1, 3, 5-10, 12-13, 1619, 24, 29, 30. All the other items are taken as it is (straight sixteen items).

$\begin{array}{lcc}\text { Ratings } & \text { Positive Responses } & \text { Negative Responses } \\ \text { Strongly Agree } & 5 & 1 \\ \text { Agree } & 4 & 2 \\ \text { Neutral } & 3 & 3 \\ \text { Disagree } & 2 & 4 \\ \text { Strongly Disagree } & 1 & 5\end{array}$

The items are scored domain wise. The Overall score gives Emotional Quotient of the student. Higher the score, higher the Emotional Intelligence

Over all EI score was compared with final semester examination marks of the college students to find out the relationship, if any, between EI and academic achievement. The data thus collected were subjected to ANNOVA to find out the relationship, if any, between EI and academic achievement 


\section{RESULTS AND DISCUSSION}

Results of the present study were discussed in Tables 2 to 7 and Figures 1 and 2.

Table 2: Relationship between Self- recognition level and academic achievement of girl students

\begin{tabular}{|c|c|c|c|c|c|}
\hline \multicolumn{3}{|c|}{ SELF -RECOGNITION } & \multicolumn{2}{|c|}{ SEMESTER MARKS OBTAINED } & F - VALUE \\
\hline GRADE & NUMBER & $\%$ & MEAN & SD & \multirow{4}{*}{$14.105 * *$} \\
\hline HIGH & 69 & 23.0 & 73.92 & 8.23 & \\
\hline MODERATE & 160 & 53.3 & 68.94 & 8.59 & \\
\hline LOW & 71 & 23.7 & 60.75 & 11.54 & \\
\hline
\end{tabular}

** Significant at $1 \%$ level

The mean marks obtained from Self - recognition, a dimension of EI, were compared with the academic performance. It was seen from the Table 2 that 69 girls are High (Very good), 160 are Moderate (Average) and 71 are Low (Poor) on Self-recognition dimension of EI. Similarly, girl students scored 73.92 as a mean score in the Very good category, 68.94 in the Average category and 60.75 in the Poor category on academic performance. The calculated FValue, 14.105 was greater than the Tabular value, hence, there was a significant difference ( $\mathrm{P}<$ 0.01) existing between the EI and academic achievement. The students, who were high on EI were also Very good in their academic achievement. Results of the present study were corroborated with the findings of Abisamra (2000), Zee, et al., (2000) and Aremu (2004).

Table 3: Relationship between Self- regulation level and academic achievement of girl students

\begin{tabular}{|c|c|c|c|c|c|}
\hline \multicolumn{3}{|c|}{ SELF-REGULATION } & \multicolumn{2}{|c|}{ SEMESTER MARKS OBTAINED } & F - VALUE \\
\hline GRADE & NUMBER & $\%$ & MEAN & SD & \multirow{4}{*}{$14.274 * *$} \\
\hline HIGH & 65 & 21.7 & 75.04 & 7.54 & \\
\hline MODERATE & 149 & 49.7 & 68.22 & 9.56 & \\
\hline LOW & 86 & 28.6 & 65.16 & 8.66 & \\
\hline
\end{tabular}

** Significant at $1 \%$ level

The mean marks obtained from the academic performance were compared with the Self regulation, a dimension of EI. Table 3 showed that 65 girls are High (Very good), 149 are Moderate (Average) and 86 are Low (Poor) on Self-regulation dimension of EI. Similarly, girl students scored 75.04 as a mean score in the Very good category, 68.22 in the Average category and 65.16 in the Poor category on academic performance. The calculated F - Value, 14.274, was greater than the tabular value, hence, there was a significant difference $(\mathrm{P}<0.01)$ existing between the EI and academic achievement. The students, who were high on EI were also Very good in their academic achievement. Results of the present study were corroborated with the research conducted by Abisamra (2000), Zee, et al., (2000) and Aremu (2004). 
Table 4: Relationship between Self- motivation level and academic achievement of girl students

\begin{tabular}{|l|c|c|c|c|c|}
\hline \multicolumn{3}{|c|}{ SELF-MOTIVATION } & \multicolumn{2}{c|}{ SEMESTER MARKS OBTAINED } & F - VALUE \\
\cline { 1 - 5 } GRADE & NUMBER & $\%$ & MEAN & SD & \multirow{2}{*}{$5.901 * *$} \\
\cline { 1 - 5 } HIGH & 50 & 16.7 & 72.82 & 8.35 & \\
\cline { 1 - 3 } & 177 & 59.0 & 69.22 & 9.35 & \\
\hline LOW & 73 & 19.0 & 66.66 & 9.94 & \\
\hline
\end{tabular}

** Significant at $1 \%$ level

The mean marks obtained from the academic performance were compared with the Self motivation, a dimension of EI. Table 4 showed that 50 girls are High (Very good), 177 are Moderate (Average) and 73 Low (Poor) on Self-motivation dimension of EI. Similarly, girl students scored 73.82 as a mean score in the Very good category, 69.22 in the Average category and 68.66 in the Poor category on academic performance. The calculated F - Value, 5.901, was greater than the tabular value, hence, there was a significant difference $(\mathrm{P}<0.01)$ existing between the EI and academic achievement. The students, who were high on EI were also Very good in their academic achievement. Results of the present study were corroborated with the research conducted by Abisamra (2000), Zee, et al., (2000) and Aremu (2004).

Table 5: Relationship between Empathy level and academic achievement of girl students

\begin{tabular}{|l|c|c|c|c|c|}
\hline \multicolumn{3}{|c|}{ EMPATHY } & \multicolumn{2}{c|}{ SEMESTER MARKS OBTAINED } & \multirow{2}{*}{ F - VALUE } \\
\cline { 1 - 5 } GRADE & NUMBER & $\%$ & MEAN & SD & \multirow{2}{*}{9.753} \\
\cline { 1 - 5 } HIGH & 27 & 9.0 & 72.66 & 9.84 & \\
\cline { 1 - 3 } & 154 & 51.3 & 70.06 & 9.21 & \\
\hline LOW & 119 & 30.3 & 60.84 & 8.13 & \\
\hline
\end{tabular}

** Significant at $1 \%$ level

F-Value of 9.753 calculated to determine relative effective of the Empathy - a domain of EI on achievement was significant at $1 \%$ level. Also the Table 5 indicated that score of 72.66 was scored by the students possessing high score on Empathy. The students, who were high on EI were also Very good in their academic achievement. Results of the present study were corroborated with the research conducted by Abisamra (2000), Zee, et al., (2000) and Aremu (2004).

Table 6: Relationship between Handling relations level and academic achievement of girl students

\begin{tabular}{|l|c|c|c|c|c|}
\hline \multicolumn{3}{|c|}{ HANDLING RE;LATIONS } & \multicolumn{2}{c|}{ SEMESTER MARKS OBTAINED } & \multirow{2}{*}{ F - VALUE } \\
\cline { 1 - 5 } GRADE & NUMBER & $\%$ & MEAN & SD & \multirow{2}{*}{13.234} \\
\cline { 1 - 5 } HIGH & 65 & 21.7 & 73.40 & 8.23 & \\
\cline { 1 - 3 } & 148 & 48.3 & 69.22 & 9.10 & \\
\hline LOW & 87 & 19.8 & 64.0 & 8.57 & \\
\hline
\end{tabular}

** Significant at $1 \%$ level 
It was seen from the Table 6 that 65 girls are High (Very good), 148 are Moderate (Average) and 87 are Low (Poor) on Self-regulation dimension of EI. Similarly, girl students scored 75.40 as a mean score in the Very good category, 69.22 in the Average category and 64.0 in the Poor category on academic performance. There was a significant difference $(\mathrm{P}<0.01)$ existing between the EI and academic achievement. The students, who were high on EI were also Very good in their academic achievement. Results of the present study were corroborated with the research conducted by Abisamra (2000), Zee, et al., (2000) and Aremu (2004).

Table 7: Relationship between Overall EI score and academic achievement of girl students

\begin{tabular}{|l|c|c|c|c|c|}
\hline \multicolumn{3}{|c|}{ OVERALL EI SCORE } & \multicolumn{2}{c|}{ SEMESTER MARKS OBTAINED } & F - VALUE \\
\cline { 1 - 5 } GRADE & NUMBER & $\%$ & MEAN & SD & \multirow{2}{*}{$11.235^{* *}$} \\
HIGH & 69 & 22.9 & 81.10 & 6.93 & \\
\cline { 1 - 5 } MODERATE & 139 & 47.1 & 69.16 & 9.09 & \\
\hline LOW & 92 & 30.0 & 65.67 & 8.65 & \\
\hline
\end{tabular}

** Significant at $1 \%$ level

Table 7 showed Handling relations between EI and academic achievement. Overall 69 girls were Very good with the mean score of 81.10 . The mean score was found to be decreasing gradually with reference to the EI. F-Value indicates that there was a significant difference ( $\mathrm{P}>$ 0.01) existing between the EI and academic achievement. Results of the present study were corroborated with the research conducted by Abisamra (2000), Zee, et al., (2000) and Aremu (2004). An emotionally intelligent student can use such skills to overcome stress and anxiety associated with test taking situation and workplace.

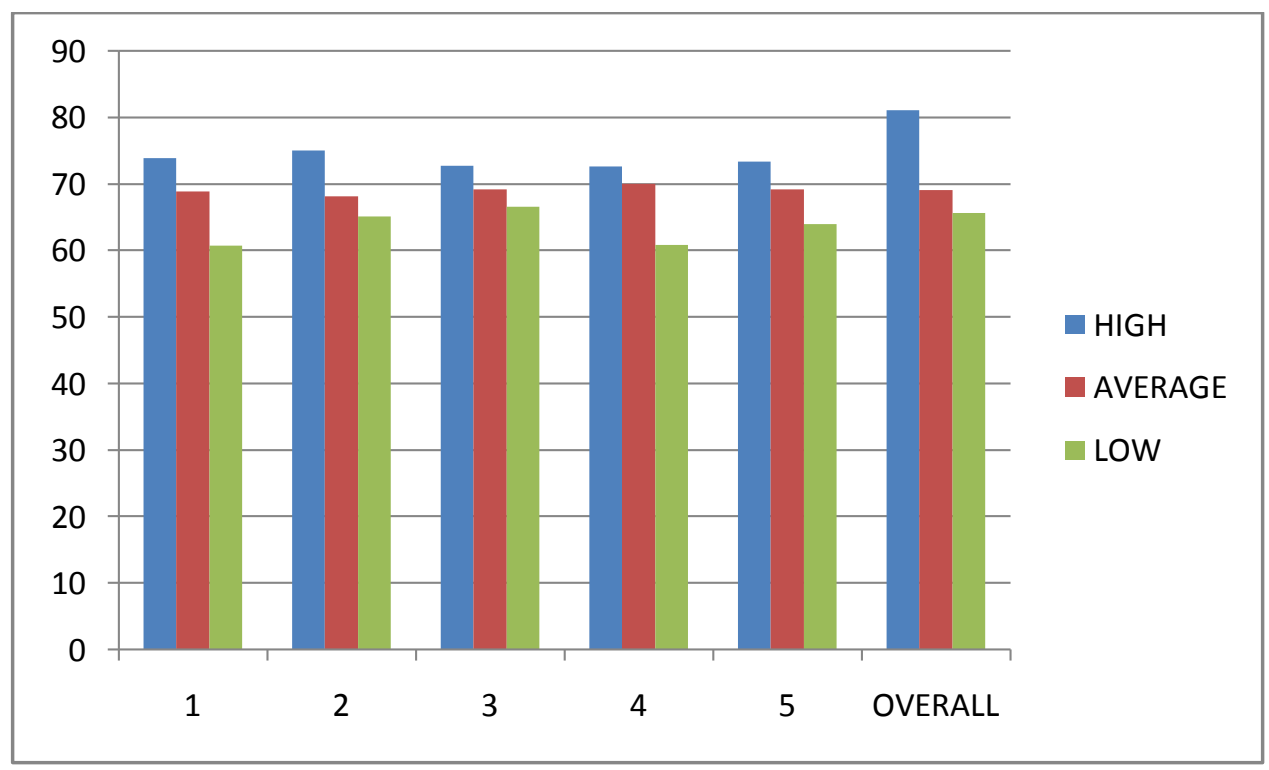

Fig 1:Level of Emotional Intelligence 
1- Self-recognition, 2. Self-regulation, 3. Self-motivation, 4. Empathy and 5. Handling relations

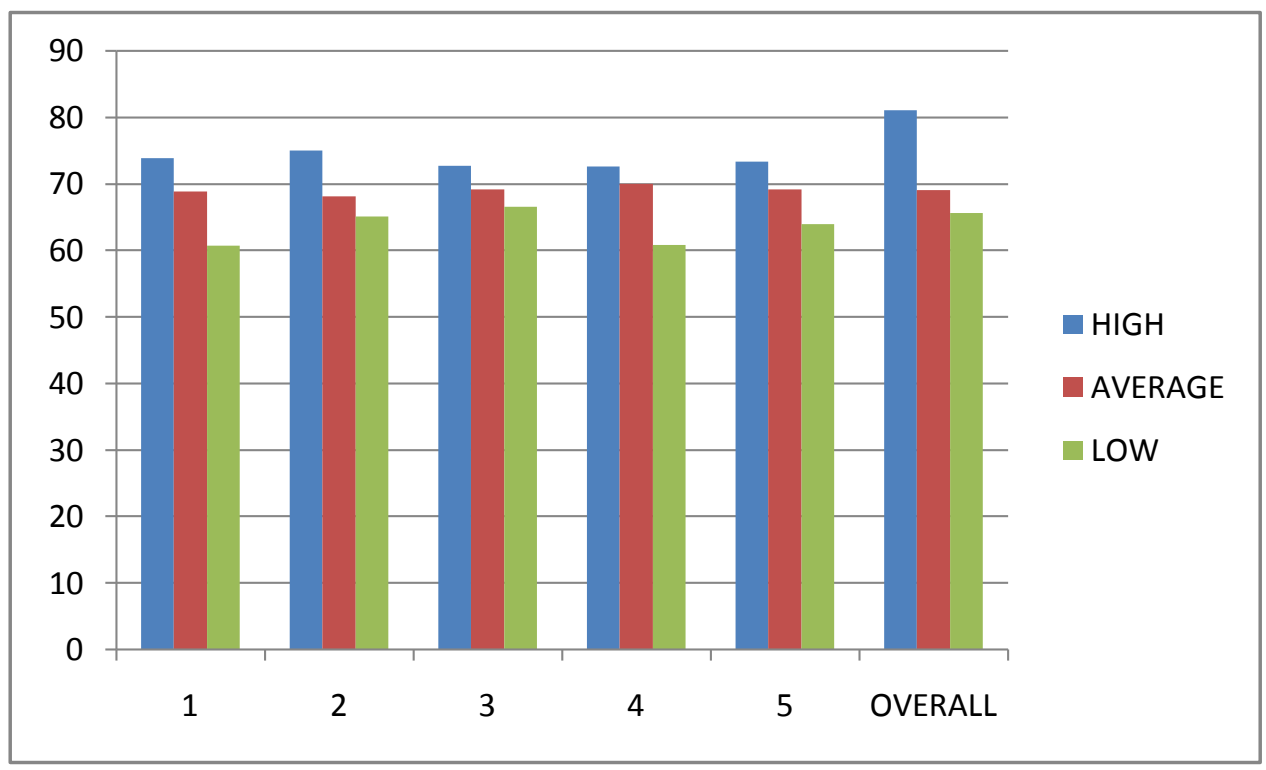

Fig 2: Academic Achievement

\section{SUMMARY AND CONCLUSIONS}

EI appears to be a core ingredient that, when developed and well employed, has wide ranging benefits for learning, relationship and wellness. Academic achievement and academic performance have been determined by variables such as family, school, society and motivational factors. However, EI plays a major role in the Academic achievement and academic performance. Hence, the present study was undertaken to find out the relationship between EI and academic achievement among Post-graduate girl students because level of maturity will be more. Psychology students were selected because they are going to be mental health care professionals.

The following conclusions are drawn from the present study:

1. EI predicts success in academic performance of the girl students

2. EI domains such as Self-recognition, Self-regulation, Self-motivation, Empathy and Handling Relations have a strong and positive relationship on the academic achievement of the girl students

3. Higher level of EI would improve employee performance and interaction in the workplace

4. Educational psychologist should encourage the development of a strong achievement motivation in the students through counselling / intervention programmes and enabling environment

5. EI promotes not only academic achievement but also success in the family / workplace 


\section{REFERENCES}

1. Abisamra, N (2000). The relationship between Emotional Intelligence and Academic Achievement.in Eleventh Graders. Research in Education. FED. pp. 620-661.

2. Aremu, A. O. (2004), Psychological and Sociological determinant of academic achievement of Nigeria Adolescents, Ife Psychologia, An International Journal of Psychology in Africa, 12, (2), pp 149-161.

3. Goleman, D. (2003) Apples and Applesauce, Issues and Recent Developments in Emotional Intelligence, Psychological Review. 1(3), pp 425-448.

4. Jaeger (2003). A conceptual framework of Emotional Intelligence in education; Factors affecting Academic Achievement. Vol XIV, No.2, pp. 41-44. Unpublished Doctoral Dissertation Texas University, Kingville.

5. Marquez Martin and Bracket, Adeyemo et.al., 2006, Emotional Intelligence and Academic Achievement, The Handbook of Emotional Intelligence, San Francisco: JosseyBass, 18, pp 304-323.

6. Nelson, D., Low, G ( 2003). Emotional Intelligence: achieving academic and career excellence. Upper Sadle River, PA., Prentice Hall. pp. 12, 102.

7. Parker, JDA., Creque, Snr. RE., Barnhart, DL., Harris, JL., Majeski, SA., Wood, LM (2004). Academic Achievement in high school; Does Emotional Intelligence matter? Personality and Individual Differences. 37 (7), pp. 1321-1329. Personality , 9, pp. 195211.

8. Dr Parthasarathy, R (29 Aug 2000). Cultivating Emotional Intelligence in Children : Role of parents and teachers. The Hindu. Daily News paper.

9. Salovey, P. \& Mayer, J .D. (1990). Emotional Intelligence, imagination, cognition, and personality, Baywood Publishing Co., pp 185-211.

10. Schutle, VX., Malonff, JM., Hajj,LE., Hagger, DJ., Coopyr, JT., Golden, CJ., Dornheim, I., (1998).Psychological Review. 25: pp. 167-77. 


\title{
ANNEXURE
}

\section{Cultivating emotional intelligence in children}

\author{
Words and actlons of parents and teachers infiuence the child's developing
self-lmage more than anything else \\ their accomplishments, ho else in the world. Consequently, praising \\ letting them to things for tharnall, would make them feel proud; \\ capable and independent. By contraselves would make them feel

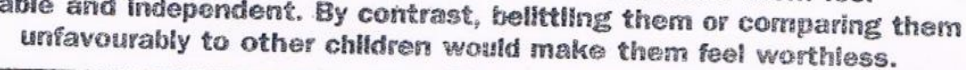

ROLE OF PAERETS AND TEACNERS

COME INDIVIDUALS, in spite of being gifted with high intelligence
(IQ), advanced degrees, or technical expertise, are neither successful nor happy in their personal and profes sional lives. Such people have been in. tensively studied and researched by tental health experts and behavioural and social scientists. A relatively new factor called 'Emotional intellisence' is being projected by experts after their study. It refers to the capacity for rec ognising our own feelings and for reccihers, for motivating ourselves, and for managing emotions well in ourselves and in our relationships. It describes abilities distinct from, but complementary to academic intelligence, the purely cognitive capacities measured by IQ.

In his book, 'Working with emotional intelligence, Daniel Goleman includes the following five basic emotional and social competencies:

Self awareness: knowing what we are, feeling at the moment, and using those preferences to guide our decision making; having a realistic assessment of our own abilities and well grounded sense of self confidence.

Self-regulation: Handling our emotions so that they facilitate ratiter than interfere with the task at hand: being conscientious and delaying gratification to pursue goals; recovering well from emotional distress.

Motivation: Using our deepest pref 1 erences to move and guide us toward our goals, to help us take initiative and strive to improve, and to persevere in the face of setbacks and frustrations.

Empathy: Sensing what people feel being able to take their perspective and cultivating rapport and atiunement with a broad diversity of people.

Social skills: Handiing emotions in relationships well and accurately reading social situations and urately readteracting smoothly; using these skills in persuade and lead, negotiate and settle disputes, for cooperation and sette work.

These five components of emotional intelligence pave the way for actualisest extent. The experis have indicat i) that emotional intelligence does not mean merely 'being nice. At strategic
moments, it may demand not 'being nice' but it may demand not 'being nice', but rather, bluntly confronting
someone with an uncomfortable but comeone with an uncomfortable bu avoiding. Secondly they have been avoiding. Secondly, emotional intelligence does not mean giving free rein to
feelings. Rather, it means managing feelings. Rather, it means managing feelings so that they are expressed ap propriately and effectively, enabling people to work together smoothly tolevel of fixed genetically, intelligence is not oniy in early y, nor does it develop which early thildhood. Unlike $1 \mathrm{Q}$, years, ernotional intelligence our teen be largely learned and it continus to develop as we go through life and learn from our experiences our competence in it can keep growing

The persokal and social competencies do not develop in a vacuurn. Our socialising process, especially the socialising agents - family and school. play a vital role in cultivating emotional intelligence in children. Here are some

Children should get exposed to a wide range of activities apart from aca demic work. They should be encouraged to participate in sports and cultural activities. By gerting involved in helping others in social service programmes, they come to know what lif given opportunities in fields liks to be ing drama songs, dance or like writ art. Many scings, dance or any kind of find it a waste of time. Beachers may ities only make one emotionally intivgent in later years.

in a sense self as babies when they see a sense of through the eyes of their near and dear ones. Their tone of voice, body lear guage, and evcry expression are absorbed by children. Words and actions of parents and teachers influence the child's developing self-image the than anything else in the world. Consequently, praising their accomplishments, however small, would make them feel proud; letting them do things for themselves would make them feel capable and independent. By contrast, belitilng them or comparing them unfavourably to other children would
make them feel worthless. Very harsh comments bruise the inside of the child side. We as blows would hurt the ort side. We have to let the child know th a parents and teachers still and ti.a even while correcting their mistak Children want and their mistak" tions as much as adults do. If explana take time to explain, they would do to wonder about our values and motives. Parents and teachers who reason with their chiliren allow them to un. derstand and learn in a nonjudgmental

Problems related to classroom management or family management need to be described to children and they need to be invited to work on a solution with parents and teachers. Children who participate in decisions are more motivated to carry them out. Television shows, magazines, books and internet children have an access to tonnes of what their children must be aware of reating

Parents spending time with their children would go a long way in makChildren feel accepted and recognised. tion they want from their parents oftenmishehave because they are assured of being noticed. Adolescents seed of need less undivided attention to their parents than younger childrem Parents should do their best to be avail able when their teenager does express a desire to talk or participate in family activities.

As far as possible, whatever qualities we expect in our children, we need to possess them ourselves friendliness, honesty, and kindness. By being a good role model the children are motivated to imbibe these uuali. ties. In other words, parents and teach ers need to develop their own emotional intelingence and strengthen it in their day-to-day life so that it gets transmitted to children.

By such exposures and opportunities provided by parents and teachers, the children would be properly moulded to acquire the qualities and skills required to be emotionally intelligent to face the competive world in the new millenni-

Dr. R. PAETHASARATHY

THE HINDU: $29^{\text {th }}$ AUG 2000 